\title{
DE TUINEEKHORENMUIS
}

\section{(Eliomys quercinus Wagn. = Myoxus nitela Schreb.)}

In Midden-Europa, met name in de bergstreken, komt eene groep van knaagdieren voor, die in hun voorkomen het midden houden tusschen eekhorens en muizen; die in hunne leefwijze meer met de eekhorens overeenkomen, maar in den bouw tot de muizen naderen. Daarom stel ik voor deze groep den Nederlandschen naam "eekhorenmuizen" voor.

Daar vóór kort het voorkomen van vertegenwoordigers van deze groep in Nederland niet bekend was, deed zich de noodzakelijkheid niet eerder voor, eene Nederlandsche benaming er voor uit te denken. Sedert wij echter weten, dat er eene soort in Zuid-Limburg wordt aangetroffen, moet er aan eenen Nederlandschen naam worden gedacht.

In Duitschland worden de knaagdieren van de bedoelde familie gewoonlijk met den naam "Schläfer ("Slapers") aangeduid, omdat zij een winterslaap hebben; maar ik zou dien naam niet gaarne overnemen, omdat hij mij al zeer weinig eigenaardig schijnt voor dieren, die behalve in den tijd van den winterslaap, alles behalve slaperig zijn; integendeel zijn zij juist bijzonder levendig, daar zij zich op de wijze van eekhorens door de boomen en struiken voortbewegen. Men noemt $z e$ in Duitschland ook wel "Haselmäuse", maar deze naam "hazelmuizen" geeft aanleiding tot verwarring, wijl men dááronder gewoonlijk slechts ééne van de drie soorten verstaat.

De naam "eekhorenmuizen" komt mij voor de bedoelde knaagdieren heel geschikt voor. In hunnen bouw verschillen zij tamelijk veel van de eekhorens. $Z$ ij hebben niet den breeden kop met het breede voorhoofd van deze laatsten, bij welke de voorhoofdsbeenderen tot een spits, scheef uitstaand ver- 
lengstuk zijn uitgegroeid, waardoor oogholte en slaapholte van elkaar gescheiden worden. De schedelvorm der eekhorenmuizen nadert veel meer tot dien der muizen: de kop is smal, inzonderheid het voorhoofd, en de snuit is spits. De oogen zijn kleiner en staan veel dichter bij elkander dan bij de eekhorens.

De eekhorens hebben 5 kiezen aan iederen kant in de bovenkaak, 4 in de onderkaak; de eekhorenmuizen hebben er in boven- en onderkaak 4; ook is de bouw der kiezen bij de beide diergroepen niet gelijk. Niet in alle opzichten echter sluiten zich de eekhorenmuizen in haren bouw bij de gewone muizen aan; zoo is bijv. het tandstelsel nog al verschillend bij deze twee familiën; maar in ieder geval staan de eekhorenmuizen toch nader bij de muizen dan bij de eekhorens.

Wat de leefwijze betreft: door de wijze, waarop zich de lang of althans vrij lang gestaarte, sierlijke diertjes door de boomen heen bewegen, gelijken zij in vele opzichten op eekhorens. En wat het uiterlijk aangaat: ééne soort, de zoogenaamde „zevenslaper" (Myoxus glis), lijkt precies op een eekhoren in 't klein; eene andere soort, de "hazelmuis" (Muscardinus avellanarius) wijst reeds door haren naam op de overeenkomst met eene muis. Meer of min tusschen beiden in staat de tuineekhorenmuis (Eliomys quercinus), welke hier nader moet worden behandeld.

Dit diertje (zie Plaat l) is zonder staart hoogstens $14 \mathrm{c}$. M. lang, terwijl de staart eene lengte van 9 à 10 c.M. heeft. De kop en de rugzijde van het lichaam zijn roodachtig grijsbruin, de buikzijde is wit. Om het oog strekt zich een schitterend zwarte ring uit, die zich beneden het oor naar achteren toe voortzet tot op den hals. Vóór en achter het oor bevindt zich eene witachtige en daarboven eene zwartachtige vlek. Het basale gedeelte van den staart is grijsbruin, het uiteinde boven zwart en onder wit. De witte kleur van den onderkant van den staart is scherp 
van den 2 warten bovenkant gescheiden. De haren van het achterste gedeelte van den staart zijn langer dan die van het basale gedeelte; deze haren worden door het diertje bij het loopen op eigenaardige wijze uitgezet, n.l. van de staart af bewogen, waardoor dit lichaamsdeel aan zijn uiteinde eenigszins verbreed lijkt. Zeer eigenaardig is, dat het diertje, wanneer het bij het uiteinde van den staart wordt aangegrepen, vaak dat laatstbedoelde gedeelte van dit orgaan in de hand van dengene achterlaat, die het aangrijpt, terwijl het voorste gedeelte van den staart aan 't lichaam blijft zitten; eene bijzonderheid, die wèl bij hagedissen en vooral bij hazelwormen voorkomt, maar - voor zoover mij bekend - bij andere zoogdieren niet wordt aangetroffen. De ooren van de hazelmuis zijn vleeschkleurig. De tuineekhorenmuis heeft mooie donkerbruine oogen, die heel verstandig de wereld inkijken. De klauwtjes van de poten zijn licht horenkleurig; de bovenste snijtanden lichtbruin, de benedenste snijtanden lichtgeel. De vrij lange snorharen zijn zwart met een wit puntje; de haren van den witten onderkant van den staart zijn aan de basis grijs, aan den top wit.

Het voedsel van de tuineekhorenmuis bestaat in de eerste plaats uit boomzaden van allerlei soort: eikels, kastanjes, beukennootjes, hazelnoten, walnoten zijn haar zeer welkom; maar zij eet ook zeer gaarne peren, pruimen, abrikozen en perziken, desnoods ook appelen; hoe zoeter en saprijker het ooft is, des te liever is het haar. Zij is zeer vraatzuchtig. Soms haalt zij stukken bast van boomtakken en stammetjes af. Naast plantaardigen, eet zij ook gaarne dierlijken kost. Zij eet met graagte allerlei soorten van insekten, en plundert_zeeri gaarne vogelnesten om zoowel de jongen als de ejeren te verslinden; dat doet ook haar grootere verwante, de "zevenslaper"; maar de soort, welke wij hier bespreken, verslindt toch meer dierlijk voedsel. In verband daarmee is zij ook meer behendig in 't klimmen en het springen van den eenen boomtak op den 
anderen. Zij kan, nog beter dan de zevenslaper, overal bij komen en allerlei dieren in hunne schuilhoeken vangen. Gaarne begeeft zich de tuineekhorenmuis in de woningen van boschwachters, in alleenstaande villa's, kortom in huizen, die gelegen zijn te midden van bosschen, parken en groote tuinen en boomgaarden, waar zij zich ophoudt; daar vergast zij zich bij voorkeur aan vette vleeschwaren, zooals ham en spek, aan boter en vet.

Het begin van Mei is de paartijd. Verscheiden mannetjes vechten dan met elkander om een wijfje, en vervolgen elkaar al sissend en snuivend, tak op tak af. De anders schijnbaar zoo lieve diertjes zijn dan razend; het komt voor dat de een den ander dood bijt en verder geheel of ten deele opeet. - Na een dracht van een kleine maand werpt het wijfje 4-6 naakte, blinde jongen, hetzij in een eigen gemaakt nest, hetzij in een verlaten nest van een eekhoren of een kraai, of wel in een nest van eene lijster of merel, dat deze eekhorenmuis dan met geweld in bezit heeft genomen, nadat zij gewoonlijk de daarin aanwezige eieren of jongen heeft opgegeten. Deze door een ander dier gemaakte nesten worden, wanneer de tuineekhorenmuis er bezit van heeft genomen, door haar nog eerst duchtig opgeknapt, en van binnen met haren, vogelveeren of mos gevoerd, nadat het zoodanig verbouwd is, dat het tamelijk wel aan alle kanten gesloten is, op eene kleine opening na voor het in-en uitgaall. Wanneer het diertje zelf een nest bouwt, dan is dat meestal een sierlijk, aan een tak bevestigd, vrij staand nest, zovals het eekhorentje maakt; terwijl zijn naaste verwante, de zevenslaper (Myoxus glis), juist altijd het nest maakt in holten in boomen of op andere verscholen plaatsen. Trouwens de tuineekhorenmuis gebruikt óók wel eens hier of daar aanwezige holten om er haar nest in te maken: zelden boomholten, maar wèl gaten in den grond, zooals mollegangen, rattegaten, verder gaten in oude muren, enz. ledere holte wordt dan steeds netjes met 
veeren, haren, mos, fijn gras, enz. gevoerd. Het is zeer eigenaardig, dat deze eekhorenmuis, die anders zoo uiterst zindelijk is, juist in zoo erge mate haar nest bevuilt. De uitwerpselen laat zij er rustig in liggen; en weldra verbreidt het nest zoo'n intensieven stank, dat men het zelfs op eenigen afstand ruiken kan. - De moeder zoogt de jongen vrij langen tijd, en sleept later een tijd lang voedsel voor hen naar het nest. Nadert men zoo'n nest als er nog jongen in zijn, en doet men pogingeu, deze eruit te nemen, dan springt de moeder woedend naar het gelaat en de handen van den indringer en kan dan soms hevig bijten. $\mathrm{Na}$ enkele weken reeds hebben de jongen de grootte van de moeder, maar blijven dan nog een poosje in de buurt van het nest ronddwalen, om voorloopig onder leiding en met hulp van de ouden het voedsel te zoeken. Zoodra zij geheel voor zich zelven kunnen zorgen, betrekt ieder van de jongen zijne eigene woning. Het volgende jaar zijn zij in staat, zich voort te planten. De tuineekhorenmuis brengt sommige jaren tweemaal een worp ter wereld; of dit geschiedt, hangt zeker af van de weersgesteldheid in den nazomer.

Reeds boven wees ik er op, dat de tuineekhoornmuis evenals al hare naaste verwanten, den winter slapend doorbrengt. Daartoe zoekt zij eene boomholte, een gat in een rots of muur, een mollegat, eene ruimte in een hoop rijs, stroo of hooi op, maar zoekt ook wel binnenshuis eene schuilplaats in een schuur, een tuinhuisje, onder eene veranda, desnoods in eene momenteel onbewoonde kamer. Daar bevinden zich dan gewoonlijk eenige exemplaren bij elkaar, dicht opeengedrongen, soms met elkander tot een kluwen samengerold. Wel slapen zij dag en nacht door, maar toch gaan zij niet in een toestand van volslagen gevoelloosheid over, zooals vele andere winterslapers (egel, vleermuis) doen. Als men ze bijv. met eene speld steekt, reageeren zij daarop door het gestoken orgaan samen te trekken; soms zelfs geven zij dan eenig ge- 
luid. Zoo zijn zij ook voor weersveranderingen in den winter niet geheel ongevoelig. Wanneer het buitengewoon zacht weer wordt, dan ontwaken zij en eten wat van den voedselvoorraad, dien zij hadden opgehoopt. Zoodra het weer wederom veel kouder wordt, hervatten zij haren winterslaap. Zij komen gewoonlijk tegen het laatst van April weer te voorschijn; dan eten zij eerst den wintervoorraad, dien zij hadden bijeengegaard, verder op, en gaan vervolgens leven zooals zij in den zomer doen.

In gevangenschap - zoo lees ik in BREHM, aan wien ook vele andere van de bovenstaande mededeelingen aangaande de leefwijze van de tuineekhoornmuis ontleend zijn - in gevangenschap doet men altiju de ervaring op, dat wannecr één exemplaar eerder in den winterslaap valt of later daaruit ontwaakt dan anderen, dit slapende individu door de anderen wordt doodgebeten en verorberd. Of zulks ook in de vrije natuur voorkomt, vind ik nergens vermeld. - Wanneer in den zomer een exemplaar eerder dan de anderen inslaapt of later ontwaakt, heeft dit voor den' betrokkene niet dat ernstige gevolg; want uit den gewonen slaap ontwaakt het diertje snel en kan zich dan verweeren; het ontwaken uit den winterslaap echter geschiedt niet dan zeer langzaam, en vóór het dier tot volledig bewustzijn van zijnen toestand is gekomen, is het reeds de prooi van de anderen geworden.

Wanneer men meerdere tuineekhorenmuizen bij elkander in gevangenschap heeft, moet men dus zorgen, dat zij door behoorlijke verwarming van het lokaal, waar hare kooi staat, niet in den winterslaap vallen. Verder ook dat voortdurend ruimschoots voedsel aanwezig is; want ook de honger is altijd oorzaak, dat er tusschen de diertjes onderling dadelijk gevochten wordt, vaak met het gevolg dat de overwonnenen worden opgegeten.

Overigens is er niet veel aan, de diertjes in gevangenschap te houden; want zij blijven wild en onhandelbaar, bijten graag, 
zitten over dag stil en maken bij nacht een hevig rumoer. De tuineekhorenmuis komt in 't algemeen voor in de gematigde streken van Midden- en West-Europa: in de Russische Oost-zeeprovinciën, Galicië, Zevenbergen, Hongarije, Oostenrijk, Duitschland, België, Frankrijk, Zwitserland en Italië. $Z$ ij komt voor ook wel op het vlakke land, maar meer in de bergstreken, liever in loofhout- dan in naaldhoutbosschen. In werken over de Nederlandsche fauna werd zij tot dusver niet vermeld. Een jaar geleden echter maakte de Heer J. STURING, Leeraar aan de Rijkskweekschool voor Onderwijzers te Maastricht, er mij op attent, dat het diertje in Zuidelijk Limburg wordt aangetroffen, en later ontving ik van hem een exemplaar, afkomstig van Valkenberg. Ook de Heer A. M. Sprenger, Rijkstuinbouwleeraar voor Limburg en oostelijk Noord-Brabrant, deelde mij mee, dat het in Zuid-Limburg vrij algemeen bekend is, dat de tuineekhorenmuis daar voorkomt. Reeds heeft de Heer STURING kort geleden in "De Natuur" een artikel geschreven over dit knaagdiertje; wetk artikel in "De Veldbode" van 6 Mei 1911 werd overgenomen (bl. 290).

Genoemde Heer meldt mij, op mijne vraag, hoe men in Zuid-Limburg de Myoxus quercinus noemt: dat daar de meesten hem "tuinslaper”, anderen hem „zevenslaper" noemen, terwijl nabij de grens de Fransche benaming "dormeur" in gebruik is. Aan den brief van den Heer STURING ontleen ik verder, dat het bedoelde diertje op den St. Pietersberg vrij algemeen is, ook in Gronsveld (aan de tegen overgelegen zijde der Maasvallei); eveneens te Valkenberg; dat hij volgens het gezegde van anderen in Zuid-Limburg nog op veel meer plaatsen voorkomt.

De afbeelding op Plaat $I$ is gemaakt naar een exemplaar, dat ik van den Heer STURING heb ontvangen.

Deze Heer schrijft, dat de tuineekhorenmuis vooral schadelijk wordt "aan fijn fruit". ECKSTEIN ') schrijft aangaande

1) ECKsTEIN, „Forstliche Zoologie”, bl. 126. 
dit diertje: „Gevaarlijk voor de ooftboomgaarden, vooral omdat het meer vruchten aanbijt dan het kan opeten." BREHM ') is vrij uitvoerig aangaande zijne beteekenis ten opzichte van de ooftteelt. Ik zal dezen schrijver hier woordelijk aanhalen: „De tuineekhorenmuis is een zeer gehate gast in tuinen, waar fijnere ooftsoorten worden geteeld. Een enkel exemplaar is voldoende om eenen ganschen perzik- of abrikozenoogst te vernietigen. Bij hare snoeperijen toont zij een smaak, die haar alle eer aandoet. Slechts de beste en meest sappige vruchten zoekt zij voor zich uit, maar knaagt ook anderen aan om ze te probeeren, en vernielt op deze wijze veel meer dan wat zij eigenlijk opeet. Er bestaat geen middel om er haar van af te houden; want zij weet iedere hindernis te overwinnen, klautert bij latwerk en boomen op, sluipt door de mazen der netten, welke er voor gespannen zijn, of knaagt deze door, wanneer de mazen te klein zijn om er door te kruipen. Zij kruiptzelfs door metaalgaas heen. Slechts dàt ooft, hetwelk laat rijp is, is voor dit diertje veilig; want tegen dien tijd ligt het reeds slapend in zijn nest."

Ook voor den boschbouw zijn de eekhorenmuizen niet zonder beteekenis, al valt niet altijd met zekerheid te zeggen, welke soort uit deze groep de schade heeft aangericht, daar in de dienaangaande meegedeelde berichten soms sprake is van "Schläfer", soms van "hazelmuizen”, maar niet nader is aangegeven, of men met den zevenslaper, de tuineekhorenmuis of wei met de hazelmuis te doen had. Want de soort, aan welker bespreking dit artikel is gewijd, wordt vaak in Duitschland met den naam "groote hazelmuis" of ook wel kort en goed met den naam "hazelmuis" aangeduid.

In een enkel geval echter wordt de tuineekhorenmuis met name genoemd als de oorzaak van het maken van "ringen" om boomstammen. Ik kom daarop nader terug, maar wijs er

1) ВREHi, „Tierleben; Säugetiere”, 2e druk; Deel II (1877), bl. 310 . 


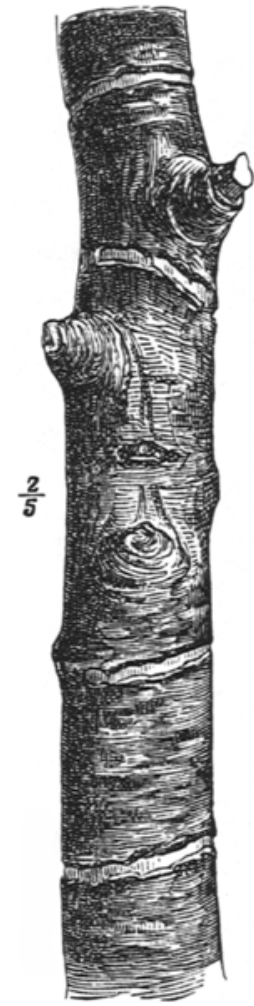

Beuk.
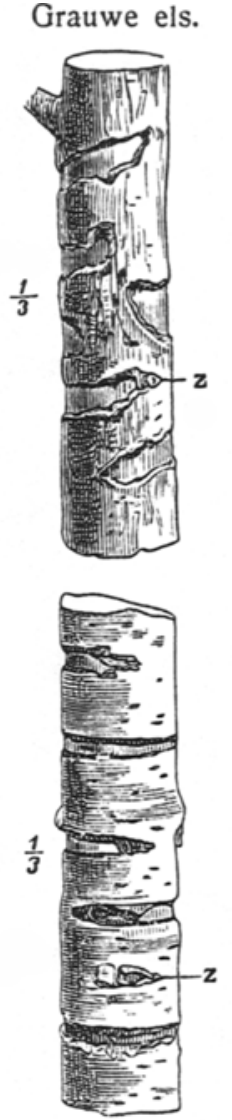

Berk.
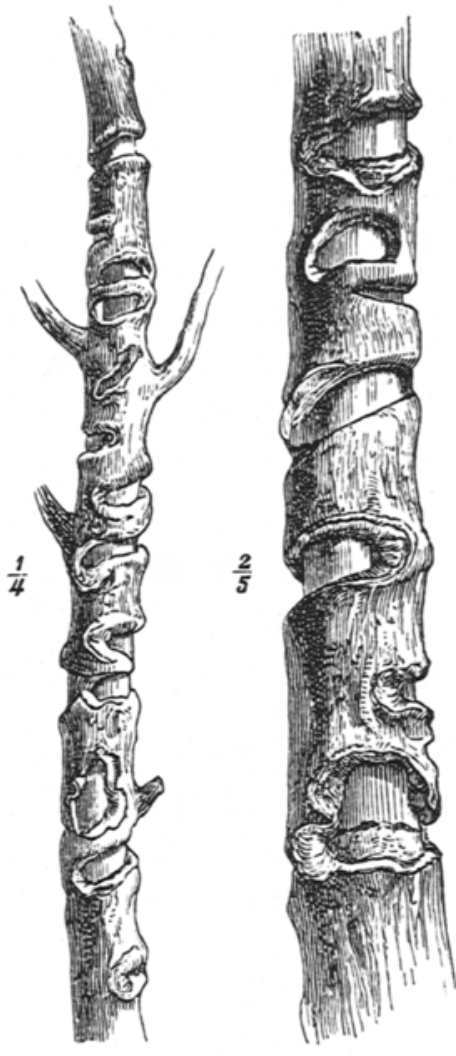

Witte els.

dadelijk op, omdat daaruit blijkt, dat de soort, welke wij hier bespreken, althans mede debet is aan de beschadigingen, geboekt staande, als door "hazelmuizen" te zijn veroorzaakt.

Men vindt zulke beschadigingen (zie bovenstaande figuren) aan beuk, haagbeuk, berk, els, hazelaar, eschdoorn, vuilboom, witbladpopulieren. Strepen bast worden namenlijk tot op het hout van jonge boomstammen afgehaald. Gewoonlijk zijn dit horizontale baststrepen, die soms zeer kort zijn, soms zich als 
een ring, soms als een spiraal met hoogstens een paar windingen, om den stam heen uitstrekken. In menig jong beukenbosch is - volgens NöRDLINGER '), aan wien de figuren op de vocrafgaande bladzijde zijn ontleend, - soms geen enkel stammetje zonder ringen, en men vindt er op verscheiden stammetjes een 20- à 30-, ja zelfs een 40-tal. Die ringen worden gemaakt deels gedurende den tijd des jaars, waarin zich de houtring vormt, deels in den tijd, waarin de boomstam in rust verkeert. In 't eerste geval wordt de stam niet slechts ringvormig van de bast beroofd, maar van dien ring uit worden nog lappen bast losgetrokken. Vooral naar den top der jonge boomen toe zijn zulke afgetrokken lappen bast soms vrij groot; de meer teere struktuur van de bastlaag en het cambium geeft daartoe aanleiding. Deze weefsels dienen den eekhorenmuizen tot voedsel, vooral in 't vroege voorjaar tentijde van de ontwikkeling der knoppen: een tijd, waarop ander plantaardig voedsel niet in groote hoeveelheid anwezig is.

De ontschorste ringen worden spoedig door wondweefsel overwald. De schade, welke op deze wijze wordt teweeggebracht, is dus niet bijzonder groot. Slechts voor berk en hazelaar, waarvan het hout gemakkelijk in ontbinding overgaat, kan de schade meer van belang zijn; de toppen, gelegen boven de geringde plaatsen, kunnen dood gaan. Het hout van de berk wordt onder de ringen zwart. Ook bij andere boomen dan berk en hazelaar kunnen evenwel door wind en sneeuwdruk de stammetjes op de beschadigde plaatsen afbreken.

In verreweg de meeste gevallen, waarin sprake is van het "ringen" van boomstammetjes door eekhorenmuizen, is het niet zeker, met welke van de drie soorten men te doen heeft. Toch is in één bepaald geval uitgemaakt, dat onze tuineekhorenmuis de misdadigster was. De „Forstgehülfe" SPEGG ${ }^{2}$ ) te

1) NördLiNGer, „Lehrbuch des Forstschutzes,” bl. 67.

") Zie AltuM, „Forstzoologie, I, Säugetiere”, 2e druk, bl. 112. 
Rothenbuch (in den Spessart) schrijft: „Bezüglich der Beschädigungen, welche die Eichelmaus (Myoxus quercinus $=$ Gartenschläfer) im hiesigen Reviere veranlasst, bemerke ich, dass solche an den Buchenstangen und Gartenhölzern des ganzen Revieres ohne Unterschied der Lage, Exposition, Bodengüte oder Bestandesbeschaffenheit wahrgenommen werden, massenhaft in einigen Waldorten, in einigen mehr vereinzelt. In der Regel beginnt der Frass an Buchen von 1 Zoll Durchmesser bei 3 Fuss über dem Boden, an stärkeren Stangen von 6 bis 9 Zoll aber erst bei 20 Fuss Höhe, und wiederholt sich dann an dem selben Stücke in unregelmässigen Abständen oft 30, 50 ja 100 mal. Die grösste Menge der Tiere wurde um das Jahr 1848 beobachtet; später nahm dessen Zahl ab, in Folge dessen auch die Beschädigungen, und jetzt werden letztere nur selten mehr bemerkt."

Behalve door het "ringen" van boomstammen kan de tuineekhorenmuis in meerdere of mindere mate in de bosschen nadeelig worden door het eten van eikels en beukenvruchtjes, en verder door het uithalen van de nesten van verschillende nuttige insektenetende vogels. De Heer Sturing ') spreekt van het doodbijten van jonge kuikens door dit knaagdiertje.

In 't algemeen zal de boschbouwer zelden aanleiding hebben om het knaagdiertje te trachten uit te roeien; de eigenaar van ooftboomen wèl. Daar het evenwel niet zeer gemakkelijk gaat, het dier te vangen of te dooden, komt in de eerste plaats het sparen van zijne natuurlijke vijanden in aanmerking. Marters, hermelijnen, wezels, uilen en verschillende dagroofvogels vervolgen en dooden het. Verder ook de katten; en wie schade van tuineekhorenmuizen aan zijn fruit ondervindt, doet dus goed, in zijnen tuin of zijnen boomgaard een paar katten te laten rondzwerven. GLOGER geeft als een middel om de eekhoren-

1) J. STURING, in "De Veldbode" van 6 Mei 1911. 
muizen te dooden aan: het neerleggen van bittere amandelen op de plaatsen, waar ze veel komen. Maar volgens NöRDLINGER en ALTUM eten zij niet graag bittere amandelen, en ondervinden zij van deze geen nadeel. Zoete amandelen eten zij zeer gaarne, en zij schijnen deze reeds op grooten afstand te ruiken. Daarom beveelt NöRDLINGER aan om, wanneer men $z e$ in vallen van ijzerdraad wil vangen, amandelen daarin te leggen als lokaas.

Volgens Hess ') vangt men ze bij Trier met behulp van ijzeren „rattenstappen", waarbij als lokaas gebruik wordt gemakkt van een stukje'spek.

Wageningen, J. RITZEMA BOS. 12 Mei 1911.

') HEss, „Der Forstschutz”, 2e druk I, bl. 143. 